\title{
A CONTRIBUIÇÃO DA IIRSA NA RETOMADA DOS INVESTIMENTOS EM INFRA-ESTRUTURA, REDUÇÃO DOS GARGALOS LOGÍSTICOS E INCREMENTO DA ATIVIDADE EXPORTADORA
}

\author{
Fátima Faro ${ }^{1}$ \\ Ricardo Faro $^{2}$
}

\begin{abstract}
RESUMO
O presente artigo apresenta e discute a IIRSA (Integração da Infra-estrutura Regional Sulamericana), como uma das ferramentas capazes de auxiliar o País a enfrentar e vencer o desafio imposto pela necessidade da realização de investimentos em infra-estrutura. Além disso, comenta o reflexo de tal iniciativa na redução dos gargalos logísticos que comprometem o escoamento da produção exportável, e ainda a sua atuação como elemento coadjuvante no incremento da atividade exportadora, sobretudo a de serviços de engenharia, um veículo natural de inserção das micros, pequenas e médias empresas no cenário internacional.
\end{abstract}

Palavras-chave: Comércio Exterior; Exportação de Serviços; Integração Regional; Investimentos; Infra-estrutura; Problemas Logísticos;

\begin{abstract}
The purpose of this article is to discuss the IRSA (South America's Infra-structure Regional Integration) and its contribution for the Brazilian Economic and Social Development, regarding the investments on infra-structure in areas such as engineering, transportation and telecommunication, the reduction of the logistic problems as well as the encouragement of the foreign trades activities, in special, the Brazilian Export of Services.
\end{abstract}

Key-words: export of services, foreign trade, investments, infra-structure, logistic problems, regional integration.

\section{Considerações Iniciais}

É consenso entre grande parte dos setores organizados da sociedade, que o progresso do País e respectivo crescimento de sua representatividade no cenário internacional está vinculado ao comprometimento da gestão pública dos recursos disponíveis, com a execução de projetos que possam viabilizar a ampliação da oferta de empregos combinada a uma melhor distribuição de renda.

Tais movimentos, adicionalmente, devem mostrar-se fortes o suficiente para provocar a redução da vulnerabilidade externa da economia, de maneira a possibilitar a geração de

\footnotetext{
1 Doutoranda em Economia pela UnB - Brasília - DF, Mestre em Economia pela Escola de Pós-Graduação em Economia da Fundação Getúlio Vargas do Rio de Janeiro, Bacharel em Ciências Econômicas pela AEUDF Brasília - DF, Consultora de empresas públicas e privadas em projetos de planejamento regional-urbanoturístico, Membro da Comissão de Especialistas do MEC e Professora do UniCEUB.

2 Especialista em Comércio Exterior com pós-graduação Lato Sensu pelo ICAT/AEUDF - Brasília - DF, Bacharel em Administração pela AEUDF - Brasília - DF, Analista Sênior da Diretoria de Comércio Exterior do Banco do Brasil S.A. e Professor Universitário.
} 
condições adequadas que permitam a elevação significativa dos níveis de desenvolvimento social e econômico sustentáveis.

No âmbito dessas discussões, ganham corpo os debates envolvendo os aspectos quantitativos e qualitativos essenciais ao equacionamento do tema, conduzidos ao amparo da política industrial, tecnológica e de comércio exterior, atualmente empreendida pelo Governo Federal.

As diretrizes que orientam esse entendimento, reconhecem a importância e a necessidade de estimularmos os setores produtivos em que o País detenha maior capacidade de alavancagem, ou mesmo aqueles, um pouco menos privilegiados, e que necessitem desenvolver vantagens comparativas.

Assim procedendo, esses segmentos econômicos estarão habilitados a operar como elementos coadjuvantes do sucesso de uma crescente e sistemática ampliação da pauta de exportação, que, por conseguinte, venha se refletir na conquista de fatias significativas das transações comerciais, observadas nesse novo mundo globalizado.

No entanto, o incremento do nível de produção e, consequentemente, de seu escoamento ao exterior, depende da formação de uma cultura exportadora que se preocupe em buscar uma maior agregação de valor aos produtos comercializados externamente.

Em conjugação com tais procedimentos, é imprescindível que sejam direcionados esforços para a redução dos gargalos logísticos e demais problemas verificados na infra-estrutura, e que contribuem negativamente para que não observemos um salto qualitativo nessa nossa performance, mesmo em face da acumulação de resultados positivos na balança comercial.

Estima-se que o advento da Parceria Público-Privada (PPP) nesse processo possa significar uma saída natural para o combate a essas dificuldades, que reduzem sensivelmente a nossa competitividade.

É provável que tal iniciativa venha a ser relevante no estabelecimento das políticas aplicáveis a esses setores, ações, que a propósito, já foram adotadas em diversos países, e cuja empreitada se revelou satisfatória.

Entretanto, o fato é que, muito provavelmente, não observaremos uma convergência dos tempos e movimentos na correlação entre o discurso e a ação, ou seja, o atendimento tempestivo às necessidades prementes, não obstante a fixação do marco regulatório, mas por quê?

A experiência brasileira no tratamento de questões de interesse nacional nos ensina que esses temas sujeitam-se a uma abordagem política, oportunista e corporativista, além de sofrer a intervenção muito forte de elementos cuja dimensão não está restrita apenas aos aspectos de ordem técnica. 
Assim sendo, talvez a dependência dessa iniciativa não seja salutar ou recomendável, e nem mesmo venha auxiliar a nossa retomada rumo a essa longa jornada, pelo menos em curto prazo.

Nesse contexto, surge a IIRSA - Integração da Infra-estrutura Regional Sul-americana, uma alternativa que talvez possa operar como um elemento capaz de contribuir, não apenas para combater os déficits de investimento em infra-estrutura, mas também incrementar a exportação, e ampliar a integração com os países vizinhos, permitindo que o Brasil possa naturalmente reivindicar o papel de líder regional que lhe cabe.

\section{IIRSA - descrição e características gerais.}

A IIRSA é uma iniciativa dos países da América do Sul com vistas a promover a integração física continental, mediante o desenvolvimento de ações com foco específico nas áreas de transporte, energia e de telecomunicações.

Considerando um horizonte temporal fixado inicialmente em 10 anos, a IIRSA não se caracteriza como uma nova entidade voltada para o fomento da região circunscrita ao continente sul-americano.

Trata-se, na verdade, de um programa de atividades conexas e sistematizadas, cujas bases para o seu desenvolvimento foram definidas a partir de um encontro realizado na cidade de Brasília - DF, em setembro de 2000, coordenado pelo então Presidente da República, Fernando Henrique Cardoso (1995 - 1998 e 1999 - 2002), congregando todos os chefes de governo dos países da região, à exceção, da Guiana Francesa.

É natural que a IIRSA não envolva a Guiana Francesa, haja vista que, em última análise, tratase de um território ultramarino sob a administração da França, cuja autonomia e capacidade própria de gestão são reduzidas.

$\mathrm{Na}$ oportunidade da fixação das diretrizes da política a ser executada por esse programa, elegeu-se como o ponto focal a identificação das iniciativas que poderiam ser adotadas para a modernização e desenvolvimento da infra-estrutura regional da América do Sul.

Procurou-se, também, encontrar saídas que permitissem estimular a organização do espaço continental, a partir da contigüidade geográfica e identidade cultural. Além disso, foram considerados, também, outros valores e aspectos de cunho social e econômico comuns ou que naturalmente fossem compartilhados entre as nações, e que, dessa forma, pudessem ser considerados num processo de aproximação de tais países.

O pressuposto da criação desse programa de ações está consubstanciado no entendimento de que a construção de uma América do Sul unida e consolidada, depende do fortalecimento de setores produtivos, cuja atividade venha contemplar a maior parcela de tecnologia e conhecimento técnico agregados. 
Acredita-se que procedendo dessa forma, é possível imprimir um ritmo de crescimento econômico sustentável, desvinculado cada vez mais da exploração de recursos naturais. Tais procedimentos, por sua vez, podem contribuir para a redução das assimetrias que permeiam os níveis de desenvolvimento observados isoladamente em cada país.

Entendem os governos dos países da América do Sul, que a formulação de uma visão estratégica que pense a região como um bloco homogêneo é um processo que somente agora começa a crescer e se tornar representativo das aspirações do continente.

Nesse sentido, é preciso harmonizar as ações convergentes para esse fim, contemplando as discussões temáticas, não apenas restrita aos líderes e autoridades de cada nação, mas que envolvam, também, os demais setores da sociedade civil.

Só assim é possível construir, com legitimidade, uma base sólida o suficiente para enfrentar as dificuldades, superar as divergências e suportar os desafios do desenvolvimento integrado.

A formatação desse plano contou com a colaboração e a participação do Banco Interamericano de Desenvolvimento - BID, da Corporación Andina de Fomento - CAF, e do Fundo Financeiro para o Desenvolvimento da Bacia do Prata - FONPLATA, que para efeito da elaboração de uma proposta de trabalho, utilizaram-se de alguns dados e insumos provenientes de outros organismos internacionais que operam na região.

Na elaboração de tal proposta, foram estabelecidos 10 eixos de integração:

I. Eixo Andino, envolvendo áreas territoriais da Bolívia, Colômbia, Equador, Peru e Venezuela;

II. Eixo Andino do Sul, envolvendo partes do Chile e da Argentina;

III. Eixo de Capricórnio, formado pela extensão de terra que compreende: região norte da Argentina; quase todo o Estado do Rio Grande do Sul; e a região norte do Chile;

IV. Eixo do Amazonas, contemplando uma faixa de terra que compreende a Amazônia Brasileira (bacia hidrográfica) e trechos da Colômbia e do Peru;

V. Eixo do Escudo Gayanés, envolvendo a região oriental da Venezuela, a Guiana e o Suriname, além do Estado do Amapá, Roraima e uma pequena parte do Amazonas, no Brasil;

VI. Eixo do Sul, estabelecendo uma conexão entre o Oceano Pacífico e o Oceano Atlântico, atravessando o sul da Argentina e do Chile;

VII. Eixo Hidrovia Paraguay-Paraná, envolvendo o nordeste da Bolívia, áreas fronteiriças do Mato Grosso e Mato Grosso do Sul, no Brasil, 
atravessando o Paraguai e a Argentina, rumo ao Oceano Atlântico, na bacia do Rio da Prata;

VIII. Eixo Interoceânico Central, formado por um eixo transversal que envolve a Bolívia, Brasil, Chile, Paraguai e Peru;

IX. Eixo Mercosul-Chile, que envolve todo o sul e grande parte do sudeste do Brasil; o Uruguai, e atravessa uma faixa de terra ao norte da Argentina, alcançando o Chile;

X. Eixo Perú-Brasil-Bolívia; formado por uma área transversal que envolve a região andina do Peru e da Bolívia, alcançando a parte oeste da Amazônia Brasileira.

Os eixos são compostos por grandes áreas geográficas cuja abrangência pode envolver diversos países.

$\mathrm{Na}$ delimitação de cada um desses eixos, foi considerado o potencial apresentado por essas extensões territoriais e suas respectivas capacidades em gerar e manter fluxos comerciais ativos.

Esses eixos foram assim formatados de maneira favorecer a formação de cadeias produtivas habilitadas a sustentar a base da atividade econômica da região circunscrita a essas faixas de terra.

Na implementação da IIRSA, tornou-se necessário dividir os trabalhos de forma a facilitar a indicação dos projetos que deveriam ser priorizados, instituindo-se, nesse sentido, três níveis gerenciais de atuação: um comitê de direção executiva, um comitê de coordenação técnica e grupos técnicos executivos.

O Comitê de Direção Executiva - CDE é integrado por representantes de alto nível dos governos dos países envolvidos nessa iniciativa, conduzidos por um presidente, dois vicepresidentes e secretariado pelo BID, CAF e FONPLATA. A presidência e vice-presidências são exercidas pelo prazo de um ano, observando-se a rotatividade entre os países membros.

Cabe ao CDE, em linhas gerais, a responsabilidade pelo desenvolvimento de uma visão e vocabulários únicos, além da orientação e sugestão de políticas a serem empreendidas na formulação das diretrizes destinadas a estruturar as áreas competentes no âmbito de cada governo , como também os planos de investimento a serem executados.

Nesse sentido, compete ainda ao CDE a análise das propostas técnicas que porventura sejam apresentadas, pelo Comitê de Coordenação Técnica, e pelos grupos técnicos de trabalho, cujas principais características e forma de atuação serão abordadas a seguir. 
O Comitê de Coordenação Técnica - CCT, integrado por representantes do BID, da CAF e do FONPLATA, atua na identificação dos projetos, considerando a visão unificada, desenvolvida e aplicada pelo Comitê de Direção Executiva. É também responsável por recomendar aos países a adoção de procedimentos destinados a mitigar as falhas e os riscos de mercado que porventura estejam presentes nos empreendimentos em princípio eleitos.

Ocupa-se, ainda, da identificação das fontes de recursos financeiros adequadas ao desenvolvimento dos projetos, qualquer que seja a origem, pública ou privada, além de cooptar o setor privado a financiar e operar os planos priorizados.

Por sua vez, aos Grupos Técnicos Executivos - GTE's, integrados por representantes apontados pelos governos dos países, cabem a realização de ações de ordem técnica, abrangendo a análise dos temas específicos, relacionados a cada eixo de integração.

Os GTE's são responsáveis, também, pela harmonização e compatibilização dos marcos normativos; identificação e avaliação integrada de projetos; realização de estudos de impacto ambiental e social; e a definição dos mecanismos institucionais de competência de cada governo, de forma a atender adequadamente às exigências ou demandas que porventura sejam apresentadas.

É interessante notar que, embora numa primeira leitura possa até parecer diferente, o BID, a CAF e o FONPLATA não participam desse programa como gestores, concentrando um alto poder de comando.

Nas suas respectivas áreas de competência, tais entidades atuam apenas de forma institucional, ou seja, de maneira a auxiliar os países, na verdade os maiores interessados na IIRSA, a definir e implementar os projetos que melhor atendam aos seus interesses.

Dessa forma, o fato de o BID estar envolvido na análise e desenvolvimento de um projeto vinculado ao "Eixo Andino do Sul", por exemplo, não significa dizer, necessariamente, que aquela organização esteja interessada em financiá-lo.

De acordo com o interesse e a conveniência dos países envolvidos, um determinado projeto, que ainda não esteja em fase de execução, pode deixar de ser prioritário e ser substituído por um outro.

\section{A importância dessa iniciativa na redução dos gargalos logísticos e incremento da atividade exportadora.}

A elevação dos níveis de exportação, entre outros fatores, depende consideravelmente da capacidade de geração de energia e da existência de uma malha viária capaz de atender as necessidades de transporte.

O grande problema observado no Brasil reside no fato de que nossas rodovias, ferrovias e hidrovias, assim como a própria estrutura instalada nos portos, aeroportos e também de serviços periféricos de apoio, apresentam basicamente o mesmo perfil retratado no início da 
década de 90, não oferecendo, portanto, as condições adequadas para o escoamento da produção exportável.

Embora não estejamos presenciando, pelo menos por enquanto, um gap de energia, e nossos reservatórios estejam bem mais cheios do que 2001, quando o seu respectivo sistema de geração e transmissão quase sofreu um colapso e provocou a necessidade de racionarmos drasticamente a sua utilização, as fragilidades desse segmento permanecem sendo observadas.

Em termos práticos, nenhuma providência foi adotada no sentido de aumentar significativamente a sua oferta, de maneira a atender às necessidades internas da população, como também conceber as condições ideais que permitam ao País acelerar o seu nível de produtividade industrial.

Tais setores, portanto, carecem de investimento, ação que aparentemente teria sido negligenciada por nossas autoridades no passado, em razão de um certo imobilismo, gerado como reflexo das políticas aplicadas a esse segmento até o fim da década de 80.

Até então aplicava-se um modelo baseado na substituição e no controle efetivo de nossas importações, ou, em outras palavras, uma certa repressão ao consumo de mercadorias, bens e serviços de origem estrangeira.

O Estado demonstrava, em princípio, uma incapacidade relativa em captar e alocar recursos financeiros na correção desses desníveis, em virtude da necessidade do direcionamento desses esforços a outros campos de atuação governamental (saúde, educação, segurança pública, entre outros).

É possível afirmar que, em face do exposto, inibiu-se a preocupação em adequar a estrutura logística existente de maneira a suportar as exigências atuais do comércio exterior, principalmente quanto a tempestividade e capacidade operacional.

Em razão disso, na opinião de muitos articulistas, os números positivos consignados na Balança Comercial poderiam ser considerados até mesmos artificiais, e por quê? Tais resultados teriam sido obtidos em virtude da falta de estímulo e inexistência de um suporte ao comércio exterior franco, que permitisse a realização de trocas desimpedidas e livres de amarras entre o País e o exterior.

Esses aspectos,certamente influenciariam a geração dos saldo comerciais evidenciados, e contribuiriam para demonstrar a ineficácia das medidas até então adotadas, e a necessidade da promoção contínua de investimentos em infra-estrutura.

De qualquer forma, no contexto da IIRSA, sob o ponto de vista da dimensão, amplitude e abrangência territorial, a posição do Brasil afigura-se por demais confortável.

A maior parte dos eixos estabelecidos acaba envolvendo o espaço brasileiro, um aspecto bastante relevante a ser considerado na priorização de projetos, até porque, pela própria 
essência dos eixos de integração, a realização de investimentos em determinado país pode interferir diretamente na economia de um terceiro.

Nesse sentido, a eventual recuperação e revitalização das vias de acesso do Paraguai ao Porto de Paranaguá, no Estado do Paraná, como também a reestruturação, modernização e ampliação da capacidade de trabalho daquele porto, ação que obviamente se faz relevante, ou em algum momento o será para o Brasil, também pode interessar aquela nação.

Afinal de contas, trata-se de um país sem saída para o mar e, dessa forma, haja vista a proximidade e ausência de obstáculos naturais representativos na sua ligação terrestre àquele porto, o Paraguai encontra em Paranaguá a via natural para viabilizar o seu respectivo fluxo comercial para com o resto do mundo.

É importante registrar que a IIRSA não concorre com o mecanismo das PPP's, e nesse sentido, as suas políticas podem ser desenvolvidas e aplicadas independentemente dos retrocessos ou avanços que a "Parceira Público-Privada" possa vir a sofrer no Brasil.

$\mathrm{Na}$ verdade, nada impede que tais ferramentas sejam utilizadas em complementaridade, atuando em prol da promoção do desenvolvimento.

Embora trate-se de uma solução bastante simplista, talvez a forma ideal de abordagem dessas questões intrínsecas à realização de investimentos e modernização da infra-estrutura existente no País, seja potencializar a utilização desses mecanismos caso a caso.

Buscar-se-ia, no âmbito da IIRSA, a priorização dos projetos em que porventura seja possível identificar e determinar o apetite das agências de fomento em financiá-los.

Por intermédio das PPP's, em consequiência, caberiam a condução daqueles empreendimentos que naturalmente se revelem interessantes para o setor privado, pelas próprias características e essência desse instrumento.

De qualquer maneira, é preciso atentar que a implementação de obras viárias de recuperação e reconstrução de nossa malha de transportes, como também de modernização da infra-estrutura portuária e aeroportuária são necessárias não apenas para recuperar o tempo perdido, mas, incisivamente, para permitir o incremento da atividade exportadora.

Nos projetos que venham a ser executados em terceiros países e cujo eixo de integração não esteja diretamente ligado ao Brasil, a IIRSA pode contribuir para o incremento da atividade exportadora, quase que de forma imediata.

Estamos nos referindo, nesse caso, a sua própria implementação no exterior, e não devido aos reflexos indiretos que futuramente venham a ser observados, em virtude da aproximação dos países, a partir da construção de novas vias de acesso e interligação, por exemplo. 
Isto porque os investimentos em energia, transportes e telecomunicações abrem uma possibilidade muito grande para que sejam exportados serviços de engenharia e atividades correlatas.

A cadeia produtiva que compõem os serviços de engenharia compreende um vasto leque de aplicações quanto à natureza e complexidade, envolvendo atividades tais como: serviços de arquitetura e engenharia consultiva; logística e suprimento; construção civil; montagem eletromecânica, posta em marcha, testes e operação assistida dos equipamentos incorporados ao projeto sob execução; serviços auxiliares diversos, além da gestão do empreendimento, caracterizada por ações administrativas, contemplando o planejamento, gerenciamento, controle e supervisão dos tempos e movimentos, materiais e pessoal.

Exportar serviços de engenharia, portanto, é executar no exterior projetos aplicando tecnologia nacional e conhecimento técnico.

Trata-se de uma iniciativa que contribui para a geração de empregos diretos e indiretos no País exportador, e opera como elemento indutor das vendas externas de bens e mercadorias.

Muitos observadores mantêm um posicionamento céptico a respeito da possibilidade de tal forma de exportação efetivamente contribuir para o incremento da atividade produtiva doméstica, principalmente porque, no caso brasileiro, poucas empresas estariam capacitadas a realizar empreendimentos com tal nível de know how e de exigência, fora do território nacional.

De fato isso é verdade, no entanto, as críticas que costumam a ser efetuadas, corroborando com esse ponto de vista, geralmente tendem a ser formuladas por aqueles não tem conhecimento efetivo acerca do comportamento do setor. Dessa forma, tais intervenientes não compreendem de maneira clara o papel desempenhado por essa atividade e seu conseqüente reflexo na economia interna, e por quê?

A execução de um projeto ao amparo da IIRSA pressupõe a identificação de fontes de financiamentos que viabilizem a sua implementação.

Geralmente, tais fontes encontram-se ancoradas em créditos públicos, uma vez que as características específicas e exigências comuns aos empreendimentos da espécie, não se revelam atrativas ao sistema financeiro privado, em virtude, basicamente, da combinação entre o custo dessas operações (somas consideráveis, na maioria dos casos), o prazo necessário para a amortização dos créditos eventualmente concedidos, e as garantias sinalizadas pelos tomadores do financiamento.

No Brasil, os instrumentos públicos existentes para apoio às exportações em sua fase de comercialização, isto é, o Programa de Financiamento às Exportações - PROEX e o BNDES- EXIM, conduzidos, respectivamente, pelo Banco do Brasil S A e Banco Nacional do Desenvolvimento Econômico e Social - BNDES, oferecem a possibilidade de assistir às 
exportações de serviços que contemplam as áreas de interesse da IIRSA, ou seja, energia, transportes e telecomunicações.

As condições de financiamento e demais parâmetros de ordem técnica presentes nos dispositivos regulamentares de cada um desses Programas, em linhas gerais, encontram-se de acordo com a prática internacional, inclusive no que diz respeito aos encargos oriundos da contratação do crédito.

Tais mecanismos determinam, entretanto, que a assistência financeira passível de ser ofertada restringe-se às exportações brasileiras.

Essa questão é de fundamental importância, uma vez que para esse efeito, não se entende como "exportação" os gastos realizados no país importador ou em terceiros países, a título da compra de bens a serem utilizados/incorporados ao projeto.

Também não são qualificados como tal, os gastos despendidos na contratação de pessoal no exterior, para a execução dos serviços vinculados ao empreendimento, objeto da venda externa.

Assim sendo, ao definirmos a exportação de serviços de engenharia, segundo a ótica e experiência brasileira, estamos querendo afirmar que todos os profissionais envolvidos na implementação do projeto, independentemente do seu respectivo nível de atuação e responsabilidade, necessariamente devem ser brasileiros ${ }^{3}$ com os salários e demais formas de remuneração pagos no País, em moeda nacional, ainda que, por se tratar de uma transação internacional, tais custos sejam cotados em moeda estrangeira de livre aceitabilidade e conversibilidade.

Da mesma forma, os bens a serem utilizados e/ou incorporados ao empreendimento somente são passíveis de financiamento, quando originários e procedentes do Brasil. ${ }^{4}$

Numa primeira análise, pode parecer improvável, ou até mesmo insano, acreditar que seja possível bancar o custo da contratação no Brasil de profissionais, com pouca ou nenhuma qualificação, para a realização de tarefas simples e que não demandem conhecimentos técnicos, arcando a empresa exportadora com o custo de manutenção desse pessoal no exterior.

Também pode parecer contraproducente a hipótese da aquisição no mercado interno dos bens de consumo que poderiam ser obtidos com relativa facilidade no local de implementação do projeto.

Esse questionamento é por demais procedente, entretanto, cabe efetuar uma observação acerca de um aspecto fundamental para o correto equacionamento da matéria.

\footnotetext{
${ }^{3} \mathrm{Na}$ verdade, os profissionais não necessariamente devem ser brasileiros. No entanto, devem estar habilitados, na forma da legislação vigente, a atuar no Brasil.

${ }^{4}$ Os bens a serem exportados devem contemplar um índice mínimo de nacionalização de $60 \%$.
} 
Independentemente de iniciativas tais como a IIRSA, a verdade é que, segundo os dados apresentados no XXIII Encontro Nacional de Comércio Exterior - EANEX, realizado em novembro de 2003, no Hotel Glória, Rio de Janeiro - RJ, o mercado internacional de exportação de serviços de engenharia encontra-se em franca expansão, e embora nossas grandes empresas tenham expertise suficiente para disputá-lo em igualdade de condições com empreiteiras originários de terceiros países, ${ }^{5}$ essa expansão se verifica com alguma expressividade nos países emergentes.

Tais países, no entanto, costumam apresentar uma certa fragilidade econômica, aspecto que dificulta a implementação dos projetos de interesse nacional, mediante o financiamento desses empreendimentos com recursos públicos próprios.

Dessa forma, as entidades estrangeiras, ao demandar as obras de engenharia priorizadas pelo país, o fazem quase que obrigatoriamente por intermédio de uma licitação internacional, buscando obter, na verdade, a execução de um empreendimento amparado na oferta de crédito externo.

Nessas licitações, além da necessidade do atendimento a critérios técnicos mínimos, essenciais para qualificação de uma empresa como postulante à execução dos serviços, exigese a oferta de financiamento em condições que não comprometam a saúde financeira do órgão licitante. 6

Assim, como no caso brasileiro admite-se financiar apenas os gastos entendidos como exportação, a execução desses projetos tende a envolver a maior quantidade de bens de origem nacional, conjugada com o maior número de profissionais oriundos do País. Isso porque a oferta de financiamento é fator de competitividade na disputa comercial que envolve a participação de uma empresa num processo de licitação.

Evidentemente que os gastos relativos aos bens de menor valor agregado, obteníveis no país importador a um custo infinitamente menor, como também os gastos relativos à contratação de profissionais que não demandem um maior nível de especialização, geralmente tendem a ser realizados no país importador, fora do âmbito dos empreendimentos. Financiados ou não por fontes alternativas de recursos financeiros, esse desenho, na realidade, não costuma implicar grandes dificuldades na formatação do crédito.

As exportadoras ou mesmo as entidades importadoras costumam batalhar, em conjunto com o país importador, pela obtenção dessas formas alternativas de crédito, exigidas para contornar

\footnotetext{
5 De fato, temos conseguido realizar obras de grande envergadura em países desenvolvidos, figurando como exemplo maior nesse sentido os Estados Unidos.

Esses países buscam geralmente, obter financiamentos que correspondam a $100 \%$ do valor do empreendimento. Tais créditos devem contemplar, ainda, um regime de amortização que preveja a concessão de um prazo de carência adequado ao projeto e a cobrança de taxas de juros inferiores aquelas praticadas nas operações privadas.
} 
a necessidade de assistir financeiramente as transações comerciais não passíveis de financiamento com recursos financeiros obteníveis no Brasil.

Com base nesse conceito, o valor do empreendimento e o valor das exportações geralmente costumam ser diferentes.

O montante do empreendimento, na verdade, compreende o somatório do valor correspondente às exportações brasileiras, acrescido dos gastos locais (não financiados), recursos financeiros próprios do importador e recursos financeiros obtidos junto a terceiros (outras fontes de financiamento).

Para a sorte do Brasil, os países latino-americanos, principalmente os vizinhos, têm apresentado um apetite considerável nesse sentido.

Como tal, em função da proximidade tanto geográfica quanto cultural, esse aspecto potencializa ainda mais a capacidade operacional das empresas brasileiras nesses mercados, em função da expertise acumulada em suas respectivas atuações internacionais, ainda mais se considerarmos o forte apelo da integração regional.

Um outro aspecto extremamente relevante que corrobora para o sucesso dessa empreitada, diz respeito à capacidade de a exportação de serviços de engenharia operar como um mecanismo facilitador da inserção no mercado internacional das empresas do segmento MPE (micro e pequena empresa) como fornecedoras dos bens e mercadorias negociados no âmbito desse tipo de operação.

Exportadoras de serviços não fabricam ou produzem mercadoria alguma, obrigando-se a adquirir no mercado interno a maior parcela de bens, mercadorias, máquinas e equipamentos necessários a suportar suas operações internacionais.

Por outro lado, a inserção das micros e pequenas empresas no comércio internacional é uma das metas preconizadas pelas políticas públicas de comércio exterior aplicadas no País. Atualmente, a maior parcela das empresas exportadoras estreantes é composta por MPE's.

Tais empresas são reconhecidas mundialmente como um fator de crescimento econômico e de estabilidade social, revelando ser muito mais ágeis e flexíveis quanto à incorporação de avanços tecnológicos do que as empresas de maior porte, e além disso, têm desempenhado um papel relevante como multiplicadoras na geração de emprego, ocupação e renda.

No Brasil, cerca da metade da oferta de trabalho é fomentada pelas MPE's, e, embora não contribuam para grandes saltos na balança comercial, seus negócios são importantes em termos quantitativos.

\section{Considerações Finais}


Setores da sociedade civil com interesse particular em questões ambientais têm efetuado críticas contundentes e bastante severas acerca da IIRSA, considerando-a muito mais como uma ameaça do que uma oportunidade.

Entendem os representantes desses segmentos ser desnecessária a inclusão da região amazônica nos eixos de integração, haja vista tratar-se de uma área ocupada por uma floresta, que apresenta uma baixíssima densidade populacional, não fazendo qualquer sentido adotar iniciativas com o objetivo de promover essa suposta integração.

A despeito do discurso oficial, ressentem-se, essas entidades, de que não estariam sendo envolvidas com maior grau de amplitude na discussão acerca do modelo de integração adequado a essa região, como também no que diz respeito ao melhor momento de aplicá-lo, de maneira a não provocar efeitos negativos e que possam comprometer o seu ecossistema.

Alega-se também, que em virtude da falta de conhecimento acerca dos estudos consolidados dos impactos sócio-ambientais, ou seja, envolvendo conjuntamente todos os eixos de integração, presume-se que a estratégia traçada na condução da IIRSA esteja prevendo a execução independente de cada projeto, interligando-os no futuro.

Agindo dessa forma, na opinião desses observadores, seria muito mais fácil driblar as eventuais dificuldades decorrentes de questões ambientais que porventura poderiam ser detectadas caso a abrangência dos estudos fosse global, e que poderiam gerar óbices e impedimentos à realização dos trabalhos.

De fato, pelo menos três eixos de integração alcançam extensões de terras da floresta amazônica, envolvendo vários países, situação que não denota alguma surpresa, uma vez que a integração física do continente é a própria razão de ser da IIRSA, e a Amazônia, abraça uma fatia significativa da América do Sul.

A gestão da Amazônia, pelo menos para o Brasil, em face de sua representatividade, independentemente de qualquer tipo de intervenção e reflexo da IIRSA na região, assume um papel estratégico nas políticas governamentais, envolvendo outras variáveis extremamente relevantes.

Podemos apontar como exemplo nesse sentido, questões tais como a segurança; defesa territorial; controle de fronteiras; e o combate à bio-pirataria, ao narcotráfico, ao contrabando e à imigração clandestina.

Afigura-se natural e compreensível, portanto, que esse tema seja abordado de forma criteriosa, reservada e confidencial por nossas autoridades, não necessariamente permitindo uma abertura maior nos seus debates e questionamentos, envolvendo o conjunto da sociedade.

De qualquer maneira, é interessante lembrar que a IIRSA não objetiva apenas integrar especificamente a Amazônia. 
Com efeito, o Brasil, em razão da amplitude de sua extensão territorial, poderia eventualmente concentrar a priorização dos projetos de seu interesse em áreas que não dependam do desenvolvimento de ações conexas e vinculadas aos eixos de integração amazônicos.

Tal conceito, entretanto, não se comporta exatamente verdadeiro quando o foco estiver voltado para a Colômbia ou mesmo o Peru, haja vista que a Amazônia é parte significativa do território daqueles países.

Em função da grandiosidade da IIRSA, algumas críticas têm sido efetuadas quanto à possibilidade de eventual distanciamento das premissas que culminaram com o seu estabelecimento, como também a ocorrência de alguns excessos ou mesmo desvios na sua implementação.

No entanto, cabe ressaltar que os três grandes atores implicados nesse processo, responsáveis por ações de fomento na América do Sul, o Banco Interamericano de Desenvolvimento, a Corporación Andina de Fomento e o Fundo Financeiro para Desenvolvimento da Bacia do Prata, historicamente têm demonstrando uma grande responsabilidade sócio-ambiental na condução de projetos dos quais têm participado.

Tais entidades demonstram uma preocupação muito grande com a exploração racional e consciente dos recursos naturais, e gozam de grande respeito e reconhecimento internacionais.

De qualquer maneira, é preciso deixar claro que a IIRSA não pode e nem deve ser considerada como a tábua de salvação para que possamos resolver definitivamente o déficit em investimento observado na infra-estrutura existente no País.

Tão pouco se revela um elemento essencial e imprescindível para que a exportação de serviços obtenha resultados satisfatórios e que venham refletir positivamente nos setores produtivos nacionais.

Também não há qualquer sinalização apontando que uma vez atingido o prazo fixado em 10 anos para a sua implementação, venha ser mantida ou descontinuada, independentemente do grau de satisfação gerado em conseqüência do alcance ou não das metas previamente estabelecidas.

De fato, as expectativas iniciais, concebidas quando da sua ativação, poderão não ser atendidas, uma vez que resta apenas mais cinco anos, aproximadamente, para alcançarmos o dead line, um prazo relativamente pequeno para a sua execução plena.

Todavia, qualquer afirmação no sentido de indicar o seu abandono ou sua continuidade carece de uma base de sustentação e deve ser entendida apenas como uma aposta ou mero palpite.

A decisão quanto a esse aspecto reveste-se de um caráter político muito forte e ,certamente, será adotada pelos países sul-americanos em face da conjuntura que venha ser observada à 
época, sendo influenciada, ainda, por outras questões relevantes e de grande repercussão na região, como o futuro do MERCOSUL e a efetivação ou não da ALCA.

\section{Referência Bibliográfica}

CASTRO, José Augusto de. Financiamentos à Exportação e Seguro de Crédito. São Paulo: Aduaneiras, 2001.

FOSCHET, Mozart. Relações Econômicas Internacionais. São Paulo: Aduaneiras, 2001 .

GONÇALVES, Reinaldo. O Brasil e o Comércio Internacional: Transformações e Perspectivas. São Paulo: Contexto, 2000.

GUIDOLIN, Benedito. Economia Internacional e Comércio Internacional ao Alcance de Todos. São Paulo: Aduaneiras, 1991.

KEEDI, Samir. Logística de Transporte Internacional: Veículo Prático de Competitividade. São Paulo: Aduaneiras, 2001.

LARRAÑAGA, Félix Alfredo. Desenvolvimento Econômico no Cone Sul: O Sistema Logístico Sub-Regional. São Paulo: Aduaneiras, 2002.

LOPEZ, José Manoel Cortiñas. Os Custos Logísticos do Comércio Exterior Brasileiro. São Paulo: Aduaneiras, 2000.

LOPEZ, José Manoel Cortiñas \& SILVA, Marilza Gama. Comércio Exterior Competitivo. São Paulo: Aduaneiras, 2004.

MAIA, Jayme de Mariz. Economia Internacional e Comércio Exterior. São Paulo: Atlas, 2001.

MARINHO, Mônica Romero Monteiro \& PIRES, Jovelino de Gomes. Comércio Exterior: Teoria X Prática no Brasil. São Paulo, Aduaneiras: 2002.

Confederação Nacional da Indústria - CNI; Serviço Social da Indústria - SESI; Serviço Nacional de Aprendizagem Industrial - SENAI; Instituto Edvaldo Lodi - IEL. A InfraEstrutura no Brasil em 2005. Brasília, 2005.

Federação das Indústrias do Estado de São Paulo - FIESP; Centro das Indústrias do Estado de São Paulo - CIESP. Contribuições da FIESP/CIESP sobre o Impacto do Gargalo na Logística das Exportações e Algumas Proposições. São Paulo, 2004. 
Governo Federal. Diretrizes de Política Industrial, Tecnológica e de Comércio Exterior. Brasília: 2003

Instituto de Estudos para o Desenvolvimento Industrial - IEDI. O Comércio Exterior Brasileiro em 2004. São Paulo, 2004.

IIRSA. [Iniciativa para Integração para Integração da Infra-Estrutura Regional SulAmericana].[S.1],2005.

Disponível em : <http://www.iirsa.org/home PORasp?CodIdioma=POR>. Acesso em: 08 abr. 2005.

RIOVIVOS COALIZÃO DE ORGANIZAÇÕES NÃO GOVERNAMENTAIS [Integração Sul-americana (IIRSA): outra integração é possível e necessária!].[S.1],2005.

Disponível em : <http://www.riosvivos.org.br/canal.php?canal=256>. Acesso em: 08 abr. 2005. 